\title{
| Preface
}

This book is an account of a Hawaiian pineapple plantation and the community in which its employees live. Its aims are not solely descriptive. The company town represents a class of communities with distinctive characteristics. An attempt is made to outline these traits as they are revealed in the pineapple plantation community of Maunaloa, Molokai, and to point out factors which have brought them into existence. The influence of techniques of pineapple husbandry and the demands of industrial employment upon the lives of employees and their families are explored analytically with special emphasis on the changes which time has brought.

Observations are made also on the characteristics of Hawaiian pineapple plantation communities as a group. I am well aware that no single pineapple town of Hawaii is truly typical of all. Each is distinctive, but all have much in common. All are "owned" and operated by business corporations, a condition which profoundly affects community life and social relationships. All have been shaped in varying detail but common outline by circumstances peculiar to Hawaii. All have common problems and have been similarly affected by changing socioeconomic conditions of Hawaii and the rest of the world. What is true of Maunaloa is in large measure true of all other Hawaiian pineapple towns.

The data assembled here were derived in part from five years of service, from 1938 to 1943, as an administrative employee of Libby, McNeill and Libby, the corporation which operates Maunaloa plantation. During most of this period I lived in Maunaloa or one of two other plantation towns of the corporation on the islands of Oahu and Maui. In the course of my work I visited Maunaloa often, and I resided there continuously for fifteen months during 1940 and 1941. Military service took me away from Hawaii in 1943, and I did not see Maunaloa again until late 1946, when a visit of a few weeks gave me some idea of post- 


\section{viii | Preface}

war conditions. After an absence of ten years, I next returned to Maunaloa in 1956, during the summer vacation from my teaching duties as an anthropologist at the University of California at Berkeley. Many of the data I have used were gathered by my wife and myself at this time.

Some knowledge of plantation communities other than those in which I have resided was gained during the period from 1938 to 1942 by brief visits, often social in nature, to most of the other Hawaiian pineapple towns. In 1956 officials of several plantations were interviewed regarding the industry in general, and factual information on personnel and mechanization was gathered for comparative purposes on four plantations in addition to Maunaloa.

Writers of books such as this customarily veil the identity of the community as a means of protecting both the people described and themselves. I have not attempted to do so because no Hawaiian pineapple plantation community can be made truly anonymous. Even a slight knowledge of the Hawaiian Islands makes identification easy. So far as possible, however, the identity of persons mentioned in these pages is concealed. Certainly I shall make no ethical judgments concerning them. The moral attributes of the people described are of concern to the objectives of this study only as they affect relations among the people themselves. Such ethical judgments as appear here are included because they are thought to shed light on attitudes and interpersonal rela. tions. All represent the sentiments of the people themselves and are so identified. For statements that may appear unflattering, I am truly concerned and wish to assure the reader that no censure or condemnation is intended on my part. For errors in fact I offer sincere apologies.

I owe hearty thanks to the management of Libby, McNeill and Libby for permission to pursue this study in 1956, for allowing my family and myself to reside in the plantation community, and for providing other useful aid. The privilege of access to records maintained by the plantation on personnel and other matters was particularly helpful, yielding a rapid and rich harvest of vital information which would otherwise have required many weeks of effort to collect. I am warmly grateful to the employees of the plantation and other residents of the community, many of whom were old friends at the time of our residence in 1956, for companionship as well as for patience in answering our many questions. Special thanks are due Mr. and Mrs. Harry W. Larson and Mrs. Sally Sunn for many things. I am indebted to the Committee on Research of the University of California at Berkeley for financial support. 